\title{
Approaches for Bridging Research and Industry
}

\author{
Ileana Hamburg \\ Institut Arbeit und Technik, WH Gelsenkirchen, Munscheidstr. 14, \\ D-45886 Gelsenkirchen, Germany \\ Sascha Bucksch \\ Institut Arbeit und Technik, WH Gelsenkirchen, Munscheidstr. 14, \\ D-45886 Gelsenkirchen, Germany
}

\begin{abstract}
The collaboration between research and industry facilitating knowledge transfer is underdeveloped particularly referring small and medium sized enterprises (SMEs). Some reasons for this situation are lack of interest from research and education institutions to support companies, poor capabilities of SMEs to recognise the importance of innovation for their businesses and competitiveness and to engage in knowledge transfer activities, existing of practical approaches that support research abut not the transfer of research results to SMEs. In these paper two approaches applied by the authors in two European projects are presented contributing to bridge research institutions and SMEs: creating practical applications of academic knowledge for entrepreneurs which are focused on the success of their business and motivate people to work together and working partnerships between industry, research and education helping SMEs to use new technologies.
\end{abstract}

Keywords: SME, Knowledge transfer, Entrepreneurs, PBL, Cloud Computing

\section{INTRODUCTION}

In many countries the collaboration between research (knowledge producers) and industry (knowledge users) facilitating knowledge transfer is underdeveloped particularly referring small and medium sized enterprises (SMEs).Small and medium sized companies (SMEs) are the heart of Europe's economy, assuring economic growth and employment in Europe. Some of them have not survived the financial crisis; others have had to innovate in order to be competitive (European Commission, 2015). There are 21 million SMEs in Europe, supplying about $85 \%$ of jobs. It is important to support knowledge transfer within SMEs because the missing of right knowledge has a negative impact on the innovation and competitiveness of SMEs and finally on the sustainable growth of the corresponding countries (Ayyagari et al., 2007). Many interactions between research institutions and companies involve large firms, being considered more durable and regular than with SMEs. Other reasons for this situation i.e. lack of interest from research and education institutions to support companies, poor capabilities of SMEs to recognise the importance of innovation for their businesses and competitiveness and to engage in knowledge transfer activities, existing of practical approaches that support research abut not the transfer of research results to SMEs (Tiwari et al., 2008).

There is often also a difference in approach between SMEs and large corporations. High tech companies look for new technologies to develop new products and services and employ researchers (i.e. auto industry). SMEs have much smaller capacity to pay and use research. 
When asked what type of research is required, most SMEs have difficulty in answering.

It is therefore important to encourage SMEs to absorb new and external knowledge for faster innovation. The importance of knowledge transfer is recognised by EU28 members and is reflected in their national programmes developed under the Lisbon strategy. Efforts to support public research institutions to improve this situation have been done within the Committee for Scientific and Technical Research (CREST).

In this paper approaches applied by the authors in two European projects are presented contributing to bridge research institutions and SMEs. The first contribution to this fact can be realised i.e. by creating practical applications of academic knowledge for entrepreneurs which are focused on the success of their business and motivate people to work together (part 2). Another contribution is by using working partnerships between industry, research and education helping them to use new technologies (part 3).

\section{PROBLEM-BASED LEARNING APPROACH}

Problem Based Learning (PBL) (Barrows, 1986) is a constructivist approach to learning that has been widely used and advocated in higher education but it is not used in companies. PBL is a learner cantered approach in which a teacher/trainer facilitates a group activity by guiding the learners in a process of inquiry. PBL could provide a number of benefits to SMEs like immediate return on investment, low cost, on the job training, thus the learning is highly contextualised and situated, practical and related to the SME's needs and sustains the organisation's competitive advantages (Hamburg, 2015). It encourages innovation, both individual and cooperative work and thinking, a greater understanding of a topic due to active learning, engaging in the material. PBL increases motivation to learn thus developing a learning culture, developing skills in critical thinking, leadership, communication, problem solving. Problem Based Learning (PBL) (Gaffar et al., 2011) is an educational approach which uses real problems to motivate staff and students for learning. The use of PBL could lead to the achievement of the following objectives

1. Better acquisition and retrieval of knowledge related to the context (problem to be solved) and to integrate many disciplines

2. Motivation of the students, and providing them with responsibility of learning

3. Development of the ability of self-learning

4. Adapting the learning to the needs of the students

5. Development of the ability to work in team

Two main characteristics of the PBL which contribute to the achievement of the objectives are interactive work in a team and the facilitator (tutor/instructor). Working in groups, students identify what they already know, what they need to know, and how and where to access new information that may lead to the solving of the problem. The role of the facilitator is to motivate the group by supporting, guiding, and monitoring the learning process. Steps which will consider in our projects by teaching PBL and corresponding questions are (PBL step by step, 2012):

1. Clarifying the task

2. Defining the problem

3. Brainstorming

4. Rating of Brainstorming outcomes

5. Formulating learning objectives to cover know 7 ledge deficits

6. Self-study of the group participants.

7. Rating of possible solutions and working out a final solution

8. Reflection and feedback of all participants 
To date, no research has been conducted into the adoption of PBL in SMEs. The Archimedes project (www.archimedes2014.eu) is an Erasmus project with partners from research, education and industry aimed at investigating the use of PBL in SMEs. Archimedes is examining how to leverage off informal learning approaches using PBL to provide SMEs with a learning approach that produces a significant impact, particularly for small businesses. Survey Monkey questionnaires, Focus Group Discussions, Case Studies have been used in this context.

PBL is supported in Archimedes by an ICT platform (www.archimedes-tiki.eu), developed by the use of TikiWiki, an open source Content Management System (CMS). The platform helps companies to solve real problems by using the steps 1-8 described below. It has also a learning role for SME staff or students wishing to be entrepreneurs. The PBL platform contains training units for facilitator/trainer and also for the learners of the group.

The figure 1 and 2 show some screen shoots of the platform.

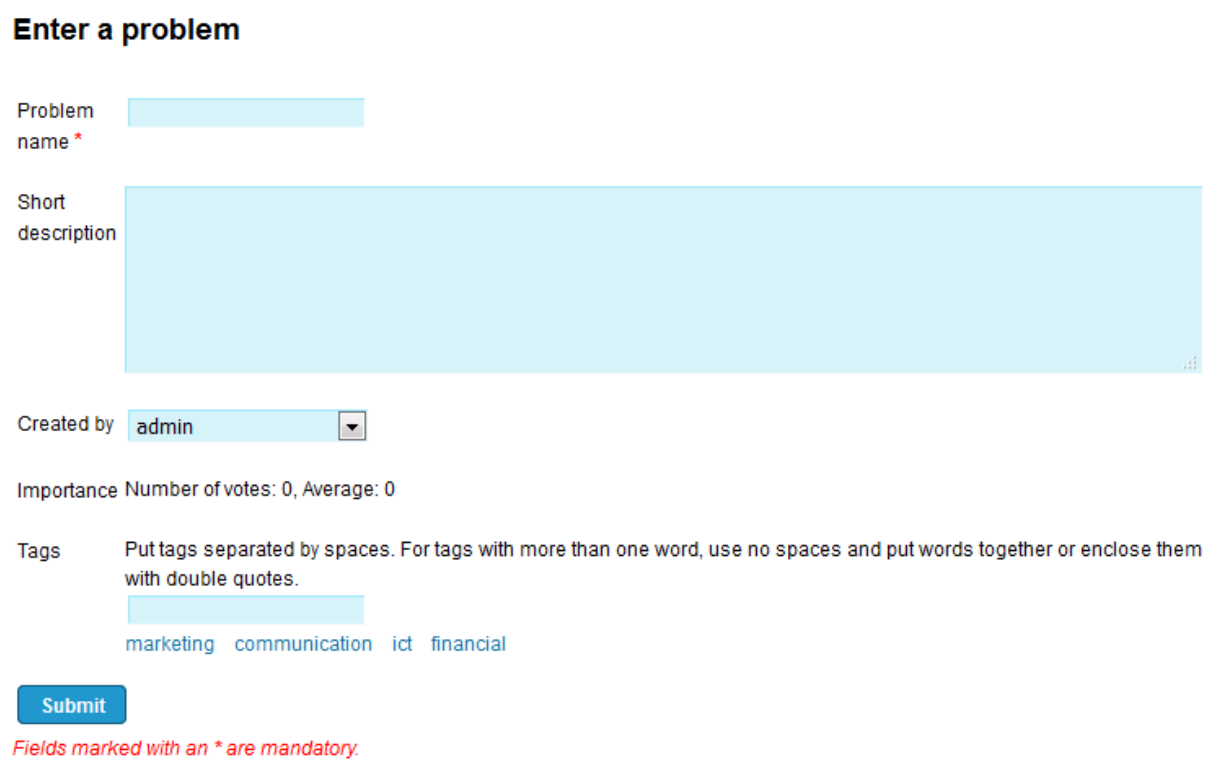

Pending problems

\begin{tabular}{|c|c|c|c|c|c|c|}
\hline & $\begin{array}{l}\text { Problem } \\
\text { name }\end{array}$ & Short description & Created by & Importance & Tags & Action \\
\hline 6 & $\begin{array}{l}\text { Cash flow } \\
\text { problem }\end{array}$ & $\begin{array}{l}\text { Some months, there is a shortfall in our income } \\
\text { versus expenditure. We find it difficult to get an } \\
\text { overdraft from the bank to facilitate us during } \\
\text { these months due to lending restrictions }\end{array}$ & emmaobrien & (1) 0 & marketing & $\begin{array}{l}\text { (30) Close } \\
\text { item }\end{array}$ \\
\hline 6 & $\begin{array}{l}\text { Printer } \\
\text { sales }\end{array}$ & Too less printers sold in the last year & admin & 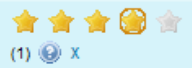 & $\begin{array}{l}\text { marketing } \\
\text { financial }\end{array}$ & $\begin{array}{l}\text { (30) Close } \\
\text { item }\end{array}$ \\
\hline 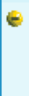 & $\begin{array}{l}\text { Distance } \\
\text { Learning }\end{array}$ & $\begin{array}{l}\text { The frustrations resulting from problems with } \\
\text { communication between student and academic } \\
\text { institution. }\end{array}$ & Winter & (1) (9) & $\begin{array}{l}\text { ict } \\
\text { communication }\end{array}$ & $\begin{array}{l}\text { Close } \\
\text { item }\end{array}$ \\
\hline 6 & money & & $\begin{array}{l}\text { Helena } \\
\text { Caiado }\end{array}$ & (0) (0) & & $\begin{array}{l}\text { Close } \\
\text { item }\end{array}$ \\
\hline 6 & Motivation & $\begin{array}{l}\text { Lately one of the key employees is not satisfied } \\
\text { and always comments on the tasks we are giving } \\
\text { to her. Although she has the biggest salary in the } \\
\text { company, she always considers herself } \\
\text { overloaded. How should we communicate withe } \\
\text { her so that we can rise the motivation level? }\end{array}$ & bestcons & (0) & communication & $\begin{array}{l}\text { Close } \\
\text { item }\end{array}$ \\
\hline
\end{tabular}

Closed problems

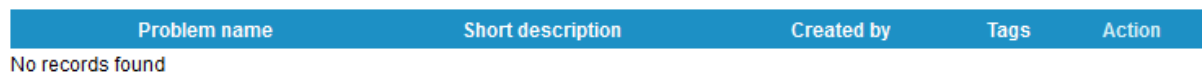




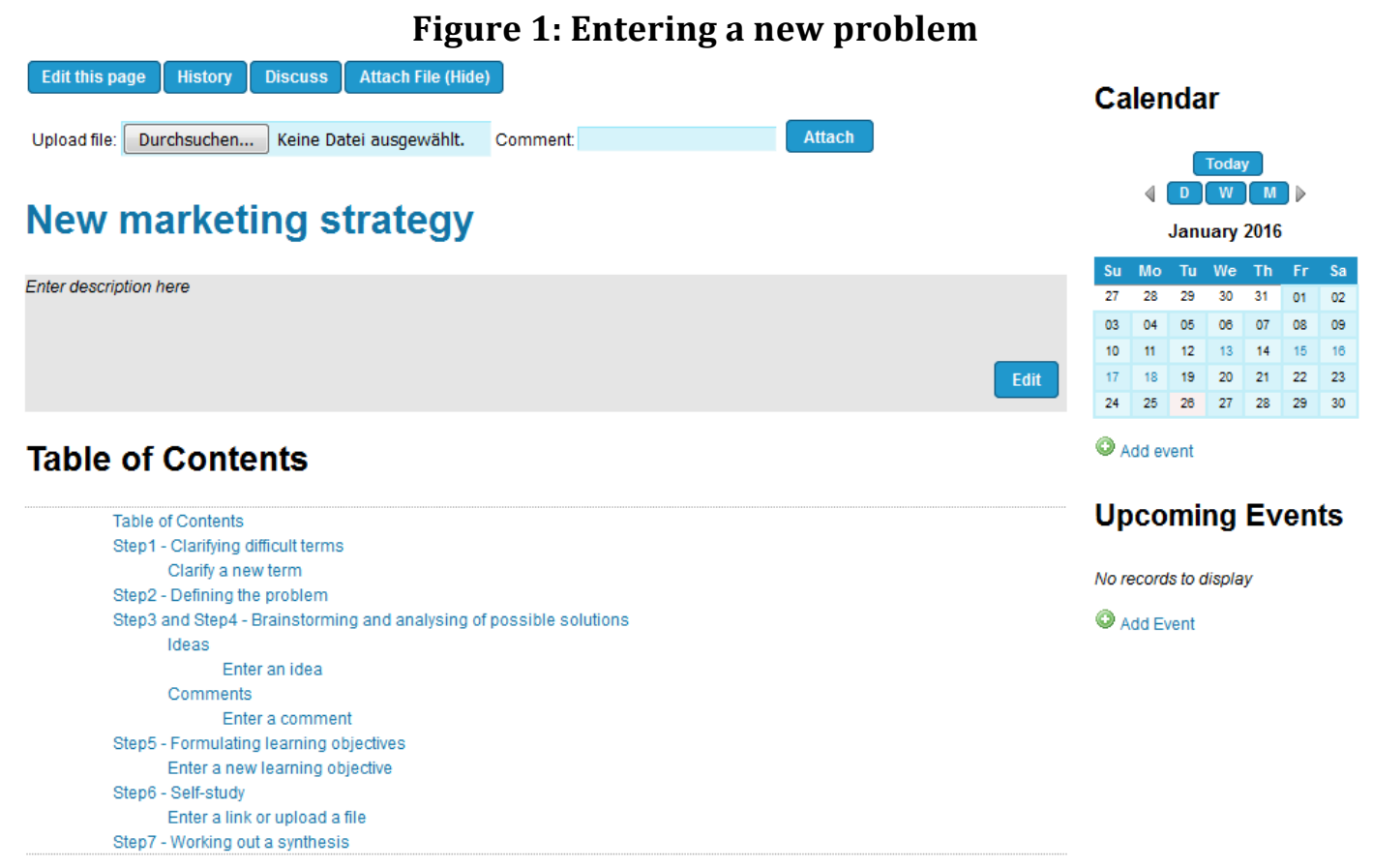

Step1 - Clarifying difficult terms

Clarify a new term

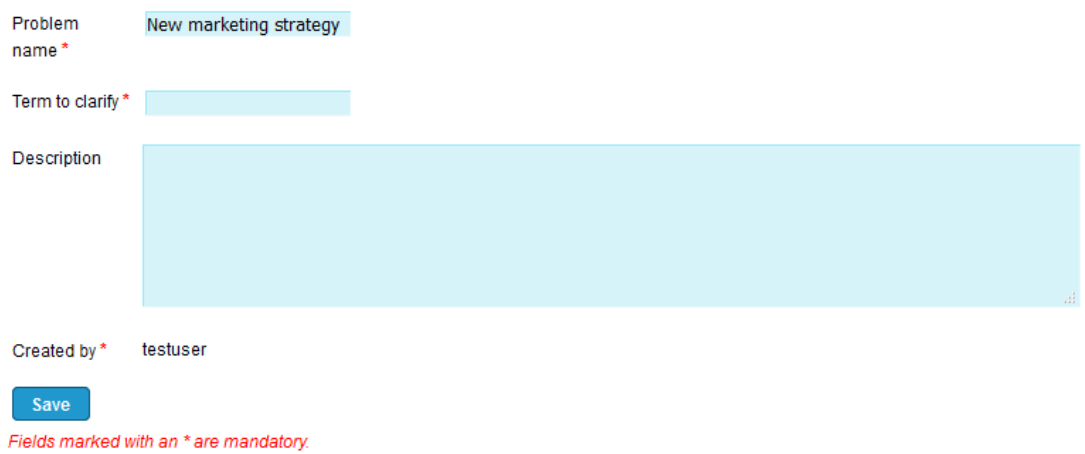

Figure 2: Supporting steps

\section{PARTNERSHIPS RESEARCH INDUSTRY TO USE NEW TECHNOLOGIES}

Recent studies emphasise the potential cloud computing (NIST, 2015) prides on in terms of boosting SMEs' growth and encouraging entrepreneurial practices at all levels (https://ec.europa.eu/digital-agenda/en/european-cloud-initiative). Still, market trends indicate European SMEs are not making the best of the cost-effective solutions cloud computing has to offer (Hamburg, 2015). Universities themselves can greatly benefit from cloud computing, as its storage capacity and economic viability ensure more efficient research management techniques in all fields.

By using Cloud services SMEs can avail of opportunities that allow them to compete in an innovative ICT environment, and give a level playing field required to succeed in business (Layo, 2013). In the discussion with SMEs, the following advantages of Cloud Computing emerged (Hamburg et al, 2013):

- Up-to-date low-cost software solutions

- Unlimited data storage

- Access to data from anywhere and anytime means portability and flexibility; giving more time and effort to be placed on business strategies and solutions

- High levels of security protocol that ensures business and data protection 
- Improved business performance

- Simplified data management

As with any technology, there are also a number of limitations or issues with Cloud Computing. One of the main issues is the reliability and security of data and the accessibility of this on a 24/7 basis, particularly when the Cloud service provider has an outage. Many companies will have problems about the lack of control over their ICT systems and the impact of a Cloud Service Provider on these (Hamburg, 2012).

These issues may inhibit an SME's decision to migrate to a Cloud Computing environment. In addition, there are other factors which may influence the decision:

- The lack of understanding of the infrastructure, cost, and appropriateness to the needs and scenarios of different companies from different business environments.

- The ICT skill levels of users, managers, and entrepreneurs.

- The readiness of SMEs to adopt Cloud Computing from a business perspective.

- Less time.

Cloud computing is thus an optimal solution for the innovation-driven alliance between universities and companies. The IN-CLOUD project intends to operate pursuing the objectives of the European Cloud Computing Strategy (https://ec.europa.eu/digitalagenda/en/european-cloud-initiative) with the general objective of - fostering a partnership between 2 research institutions, 4 Universities, and 3 SMEs associations from 5 European countries, in order to qualify new professionals able to boost the competitiveness and growth of European Companies and Universities, thanks to the advantages offered by the cloud computing technology. This objective is reached by raising awareness among European Companies during workshops and discussions with SME staff, using results of questionnaires sent to SMEs(by Survey Monkey)about possibilities to cooperate with SMEs and about cloud computing forms suitable for them. The sent questionnaire contains questions about general company information, software usage and cloud computing. It was created with the help of Survey Monkey, an online survey development cloud-based company. It provides free, customizable surveys, as well as a suite of paid back-end programs that include data analysis, sample selection, bias elimination and data representation tools. Each partner searched for studies, publications, reports and projects about cloud computing.

The questions sent in all partner countries are the following:

- What is your job role?

- How does your business/organization use IT on a daily basis?

- Do you use cloud computing services in your business/organization?

- Why don't you use cloud computing services in your business/organization?

- Which cloud computing services do you use within your business/organization?

- What benefits does the cloud offer to your business/organization?

- Which cloud services do you aspire in the future to use in your business/organization?

- Please rank your primary concerns regarding the adoption of cloud computing into your business/organization

- Which of these skills and competences, required for successful implementation of cloud computing, does your business/organization have?

The project IN-CLOUD researches also the economic impacts of cloud computing on different types of SMEs. The first conclusion is that it depends on region and sector; the IT sector mainly will have the most advantages. This impact in Europe will depend on how service providers, 
governments and managers understand it. European cloud services providers need to offer competitive prices and guarantee safe and reliable technology.

Governments need to ensure an appropriate legal environment, procurement practices and energy prices. It will also depend on the willingness of managers to adopt the new practices necessary to exploit the technical and economic advantages of cloud computing.

Cloud computing requires also new skills i.e. which are the bases for the development of didactic units within IN-CLOUD i.e.:

- Business and financial skills

- Technical skills

- Project management skills

- Contract and vendor negotiation

- Security and compliance

- Data integration and analysis skills

- Mobile app development and management

The project IN-CLOUD will create VET qualifications for professionals inside European Companies and training SME staff to achieve the required skills by using developed didactic units. This training helps ME them to introduce and manage cloud computing technologies and services inside their organisations in order to achieve their business goals.

\section{RESULTS}

The first version of the Archimedes platform has been tested with students wishing to be entrepreneurs and staff from SMEs. The results are positive. Both students and SME staff consider PBL as a suitable form for learning and solving real problems. At two academic cooperation partners PBL has been introduced in the courses for entrepreneurs. The improvements, proposed by the users, are taken into consideration for further project developments (Hamburg et al., 2014).

The IN-CLOUD project started in September 2015.At the moment the 700 results of answers from researchers, educators, SME staff from all partner countries are analysed in order to determine the next steps in the project i.e. the development of didactic units for qualification of SME staff.

\section{CONCLUSIONS}

The work in tandem of research/education and industry, particularly SMEs, to transfer knowledge to society and particularly to entrepreneurs (having a key role to innovation) are a motor for economic grow. The research interests of academics and industry are often quite different but there are possibilities to do research that can interest and help industry. First, it is important to understand industry needs and cooperate with it. There is also necessary to identify research gaps and ask industry if they are interested in these topics.

Some future strategies in this context could be to cooperate with industry bodies to identify research gaps, to explain the research process, results and how long it takes, to produce them in a form that can be used by industry.

Some research questions which for future work of the authors are i.e. which are the criteria for a smooth relationship between research/education and industry, how could be inherent differences between work and objectives of companies and researchers to form a higher strategic partnership? Is another kind of practioners needed to translate knowledge? 
ACKNOWLEDGMENTS

This paper describes progress work within the ongoing Erasmus+ projects Archimedes and INCLOUD,

\section{References}

Ayyagari M., Beck T., Demirguc-Kunt, A. (2007): Small and medium enterprises across the globe. Small Bus Econ, 29: pp. 415-434.

Barrows, H.S. (1986): A taxonomy of problem-based learning methods. Medical Education 20: pp. 481-486.

European Commission (2015): Annual Report on European SMEs 2013/2014: A Partial and Fragile Recovery, p. 10. http://ec.europa.eu/growth/smes/business-friendly-environment/performance-review/files/supportingdocuments/2014/annual-report-smes-2014_en.pdf. 2014. Accessed on December 28, 2015.

Gaffar, A.M., Abdalla, M.E. (2011): The Seven Steps of PBL Implementation: Tutor's Manual

Hamburg I. (2012): Learning as a service - a cloud-based approach for SMEs. The Fourth International Conference on Advanced Service Computing, Service computation 2012. July 22-27, 2012, Nice, France, pp. 53-57.

Hamburg I., Marian M. (2012): Supporting knowledge transfer and mentoring in companies by e-learning and cloud computing. ICWL 2012 International Workshops, KMEL, SciLearn, and CCSTED, Sinaia, Romania, September 2-4, 2012; revised selected papers. Heidelberg: Springer: pp. 231-240.

Hamburg, I. (2015): Improving e-Learning in SMEs through cloud computing and scenarios. In: Gradinarova, B. (ed.): E-learning - instructional design, organizational strategy and management. Rijeka: InTech: pp. 481-498.

Hamburg, I., and O’Brien, E. (2014): Using strategic learning for achieving growth in SMEs. Journal of information technology and application in education 3(2): pp. 77-83.

Hamburg, I. (2012): Guidelines for increasing the adoption of cloud computing within SMEs. Cloud Computing 2012: The Third International Conference on Cloud Computing, GRIDs, and Virtualization, 2012(b). pp. 7-10.

Hamburg, I. (2015): Learning approaches for entrepreneurship education. In: Advances in social sciences research journal 3, no. 1, pp. 228-237.

Layo, I. (2013): Cloud computing advantages for SMEs. http://cloudtimes.org/2013/09/18/cloud-computingadvantages-for-smes/. Accessed on December 28, 2015.

National Institute of Standards and Technology, NIST (2011): The NIST Definition of Cloud Computing. http://csrc.nist.gov/publications/nistpubs/800-145/SP800-145.pdf. Accessed on December 28, 2015.

Tiwari R., Buse S. (2007): Barriers to Innovation in SMEs: Can the Internationalization of R\&D Mitigate Their Effects. http://iri.jrc.ec.europa.eu/documents/10180/12569/Barriers\%20to\%20

innovation\%20in\%20SMEs\%20-\%20Can\%20the\%20internationalization\%20of\%20R\%26D

\%20mitigate\%20their\%20effects? Version=1.0\&t=1369908833719. pp. 3-9. Accessed on December 28, 2015. 